\title{
POR QUE O MAM DEU CERTO
}

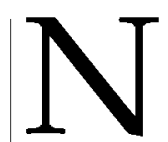

os últimos seis anos, o Museu de Arte Moderna de São Paulo - MAM - se converteu num dos mais fervilhantes pólos de cultura do país. $O$ visitante que entra no museu mal suspeita que até 1994 a instituição vivia uma crise crônica que a obrigava a conviver com público escasso, falta de patrocinadores e o risco permanente de ter seu acervo deteriorado por goteiras e cupins.

Ao passar pelos corredores e salas de exposição, o que se vê hoje é a vibração de um museu em ebulição. O MAM descobriu sua vocação e se converteu no que costumo chamar de um museu vivo, realmente orientado para a propagação da cultura, sustentado por um projeto de longo prazo.

A trajetória para se chegar até aqui não foi fácil. Mas o instigante desafio de transformar esta instituição, criada em 1948 por Cicillo Matarazzo, num exemplo para os museus do país, foi consistente o bastante para ajudar a superar os poderosos obstáculos que encontramos no processo.

E como chegamos lá? Se pudéssemos reduzir ao essencial, diria que o MAM sobreviveu e cresceu extraordinariamente porque adotou uma gestão profissionalizada, que assumiu seu compromisso com a sociedade. Desde o início do projeto, procuramos estudar os modelos adotados por alguns dos mais importantes museus do mundo.

Antes de reformarmos o que já se apresentava como inviável, percorremos os bastidores daquelas instituições que seriam e continuam sendo nossos benchmarkings (marco de referência). Do Louvre parisiense ao MoMA (Museum of Modern Art) nova-iorquino, antes de colocarmos em andamento o projeto MAM, aprendemos como vivem e respiram as mecas da museologia contemporânea.

As lições que tiramos dessa imersão foram essenciais para o início de nossa empreitada e resultaram num projeto único. 
A mescla de modelos nos fez pensar que o MAM deveria ser um espaço interdisciplinar, um laboratório de idéias a serviço da comunidade. É para ela que dirigimos tocos os nossos esforços.

Para suportar esta diretriz básica e oxigenar o inuseu, criamos uma estrutura de caplação de patrocínios. Quando assumimos a gestão do museu, o MAM contava com poucas empresas em sua carteira de colaboradores institucionais. Revimos as regras, lornamos claros os benefícios e investimos na abertura de canais de relacionamento. Batemos de posta em porta, amealhamos quatro patrocinadores em 1997. No ano seguinte, foram 25. Em 1999, batenos a marca de 43 e, em 2000 . lechamos com cerca de 50 empresas contribuindo para o MAM.

$O$ investimento loi todo convercido na expansão das atividarles do museu. Seguindo a vocação multidisciplinar, em 1998 foi constituído o Educativo MAM, que, como o próprio nome sugere, promove uma série de atividades ligadas à educação, como monilorias gratuitas para escolas públicas e privadas, grupos de terceira idade e instituiçôes em geral, cursos, palestras, shon's (Acústico MAM e Aeroporto MAM) e cinema (Cinemam) graluilo, apresentando ciclos de impoltantes diretores a cada nova exposição. Os educadores, membros fixos do staff, são, em sua maioria, jovens com nível superior, entre os quais se clestacam artistas plásticos, arquitetos, graduados em fïlo- sofia, ciências políticas e outras profissões.

O sucesso de público e crítica das mostras refletiu em prestígio e credibilidade. Só no ano passado, a curadoria organizou 40 exposiçñes sediadas no MAM e nas extensões do museu. Em 1998, o acervo contava com 2.551 obras de arte. Alé o primeiro semestre deste ano, entre aquisições, obras doadas pol empresas por meio da lei Rouanet e doaçōes de artistas, este número subiu para 3.280 obras, assinadas por 881 artistas diferentes.

Um dos símbolos desta recuperação do acervo - e do próprio renascimento do museu, já que, em 1963, todo os bens imóveis do MAM, incluindo ácervo de cerca de 2.000 obras, foram doados à Universidade de São Páulo para a criação de um novo museu - ć o Panorama da Arte Brasileira, inaugurado em 1969, com a característica de mapear o que há de mais signilicativo na contemporânea produção plástica de lodo o território brasileiro.

Exposição de início anual e hoje em dia bienal, o Panorama servíu não apenas para colocar o MAM, mais una vez, dentro do calendário artístico do país, mas serviu, também, para a ampliação de sua segun-

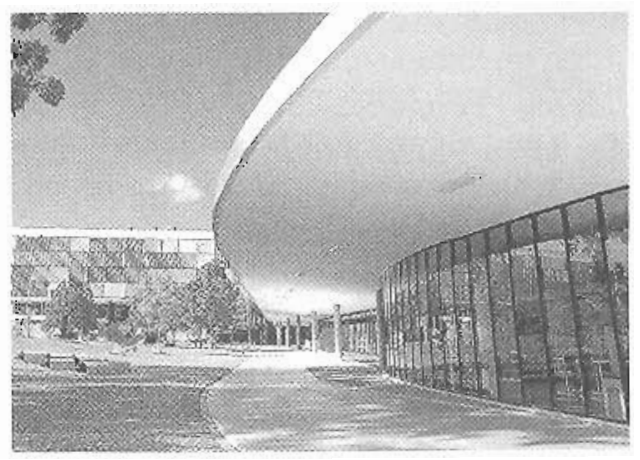

Fachada do Museu de Arte Moderna - MAM, no Parque do Ibirapuera, Sāo Paulo. 
da coleção, de início, com apenas 40 obras. Explica-se: todos os prêmios concedidos durante as edições do Panorama são sempre aquisitivos e revertidos para o desenvolvimento do acervo do museu.

Não é só. Além do cuidado em ampliar a coleção, a nova gestão está preocupada, também, em preservar seu patrimônio. Por conta disso, estabelece intercâmbios com fundações culturais, brasileiras e internacionais, no sentido de conseguir recursos para desenvolver trabalhos de recuperação e restauro das obras da coleção, tarefa que visa à preservação de um patrimônio que é, antes de tudo, público.

Às preocupações com o acervo somase a ampliação do leque de exposições temporárias no museu.

A linha curatorial adotada nestes últimos anos tem por objetivo levar ao público exposições de artistas brasileiros e internacionais representativos das artes visuais dentro do período posterior às grandes guerras.

Em síntese, a programação constitui-se, ano a ano, de mostras individuais de nomes brasileiros com criações da década de 50 para cá, de coletivas de nomes contemporâneos - emergentes ou não - $\mathrm{e}$ de artistas do circuito internacional do século XX, com destaque àqueles que aplicam novas mídias em suas obras.

Servem de exemplo as exposições de
Anita Malfatti, José Roberto Aguilar e Miró, em 1996; Carlos Zilio, Iole de Freitas, Robert Mapplehorpe e Gary Hill, em 1997; os concretistas da coleção de Adolpho Leirner, os modernistas latinoamericanos da coleção Costantini e Anselm Kieffer, em 1998; Lygia Clark, Franz Weismann e Raoul Dufy, em 1999; Cildo Meireles, Nuno Ramos e o expressionismo alemão, em 2000; e Antonio Dias, Vik Muniz e Steve McQueen, integrantes da programação deste ano.

\section{EXTENSÕES}

Em meados de 1998, percebemos que o museu começava a ficar apertado. O espaço físico de $3.500 \mathrm{~m}^{2}$ disponível para todas as atividades pedia um novo museu, onde coubessem todas as idéias da equipe. Enquanto um novo MAM não chega, procuramos outras alternativas. Por que não montar vários espaços com a nossa grife espalhados pela cidade? Através de uma parceria com a Rede Plaza, ensaiamos os primeiros passos para fora do museu: inauguramos um Shopmam no Shopping Paulista, onde comercializamos produtos com a logomarca do museu e artigos de designers brasileiros. Apesar de pequeno (a loja tem apenas $9 \mathrm{~m}^{2}$ ), a abertura do espaço foi o empurrãozinho de que precisávamos para os outros braços do museu que viriam em seguida.

Em outubro de 1999, uma nova parceria levava novamente o MAM para além das fronteiras da marquise do Parque do Ibirapuera. Inauguramos o MAM Higienópolis, com o apoio do Shopping Pátio Higienópolis e patrocínio da Telesp 
Celular, numa construção do início do século tombada pelo patrimônio histórico, um projeto de Ramos de Azevedo transformado num atraente centro de cultura no coração do bairro.

O espaço, além de receber exposições periódicas de arte contemporânea com entrada franca, organizadas pela equipe de curadoria do museu, conta com um Shopmam onde podem ser encontradas de peças de vanguarda assinadas pelos irmãos Campana até objetos do mais autêntico artesanato brasileiro. O espaço tem também os mais variados cursos: cidadania, teatro para crianças, adolescentes e adultos, Internet, pintura.

Em maio de 2000, com o patrocínio do Shopping Villa-Lobos, lançamos mais um empreendimento de sucesso, o MAM Villa-Lobos, a primeira iniciativa do gênero no mundo dentro de um shopping center, com sala de exposições com $100 \mathrm{~m}^{2}$, loja e, de quebra, um mezanino onde são ministrados cursos. O espaço tem recebido visitação recorde. Nos finais de semana, o número de visitações às exposições chega a 2 mil pessoas ao dia, o que comprova ser infundado o preconceito de alguns em relação a um museu dentro do shopping.

No mesmo mês, a extensão ganhou o prédio da Nestlé da avenida Engenheiro Luís Carlos Berrini. Dentro da proposta de proporcionar lazer e cultura para seus mais de 1.500 funcionários, a empresa convidou o museu a participar do projeto. Assim, o MAM ganhou uma sala de exposições climatizada, ao lado de uma sala para fitness (ginástica) e da lanchonete. Em junho, a Nestlé disponibilizou o espaço para visitação do grande público.

Vale salientar que todas as iniciativas têm sido lançadas com critério. No caso dos espaços para exposições, todas as normas da moderna museologia têm sido respeitadas.

Fatores como segurança e temperatura ambiente são sempre levados em conta quando o que está em jogo são as obras de arte.

$\mathrm{O}$ aproveitamento máximo do prédio que é sede do MAM gerou mais um espaço de exposição, o Projeto Parede. Atividade pioneira no Brasil, o projeto apresenta propostas de artistas brasileiros concebidas especialmente para o espaço que interliga as duas salas do museu. Desde seu início, em 1996, nove nomes participaram da iniciativa. Neste ano, Paulo Buennos, de janeiro a julho, e Nelson Leirner, de agosto a dezembro, apresentam suas obras.

O resultado de todo esse trabalho surge no aumento consistente do público. Em 1994, 9.822 passaram pelo museu. Em 1995, houve uma ligeira reação, com o ingresso de 12.970. Em 1996, este número saltou para 109.393. O crescimento tem sido progressivo. Em 1999, 172.109 viram as exposições do MAM e, em 2000, recebemos um total de 341.819 visitantes, número que superou nossas expectativas. 
Resumo: O Museu de Arte Moderna de São Paulo - MAM - converteu-se, há pelo menos seis anos, num dos mais fervilhantes pólos culturais do país. Desenvolveu sua vocação de preservar e exibir arte brasileira e internacional do século $X X$ e tornou-se, de fato, um museu vivo, orientado para a propagação da cultura, sustentado por um projeto de longo prazo. Fundado em 1948 por Cicillo Matarazzo, o MAM passou a adotar, a partir da segunda metade da década passada, uma gestão profissionalizada, que assumiu seu compromisso com a sociedade. Estruturada sobre um projeto interdisciplinar, a instituição faz-se, agora, um laboratório de idéias a serviço da comunidade.

Palavras-chave: Museu de Arte Moderna de São Paulo, arte contemporânea brasileira, museologia, acervo, política cultural, serviços comunitários
(Why the mam worked)

Abstract: The São Paulo Modern Art Museum - MAM - has become, at least in the past six years, one of the most fervent cultural poles in the country. It developed its vocation to preserve and exhibit $20^{\text {th }}$ Century Brazilian and international art and, in fact, became a live museum, turned to the propagation of culture, supported by a long term project. Established in 1948 by Cicillo Matarazzo, the MAM adopted, as of the second half of the past decade, a professional management, that tookon its commitment with the society. Structured on an interdisciplinary project, the institution is now a laboratory of ideas at the service of the community.

Key words: São Paulo Modern Art Museum, Brazilian contemporaneous art, museology, collection, cultural policy, community services 